\title{
UMA ANÁLISE DO IMPACTO DO PROGRAMA BOLSA \\ FAMÍLIA NA REDUÇÃO DO TRABALHO INFANTIL NO \\ BRASIL ENTRE 2004 E 2011
}

\author{
AN ANALYSIS OF THE IMPACT OF BOLSA FAMÍLIA \\ PROGRAM IN REDUCING CHILD LABOUR IN BRAZIL \\ BETWEEN 2004 AND 2011
}

\author{
Ludmila Giuli Pedroso* \\ Lucilena Ferraz Castanheira Côrrea ${ }^{* *}$
}

\begin{abstract}
RESUMO
Dado à grande importância do Programa Bolsa Família (PBF) em auxiliar imediatamente às famílias pobres no aumento de renda e o cumprimento das condicionalidades para o recebimento do benefício, tornou-se pertinente verificar o impacto indireto do Programa sobre as crianças que exercem alguma atividade de complementação de renda familiar. Desse modo, com o aumento da frequência escolar mínima exigida para a permanência no Programa, pretende-se verificar se houve redução dessa mão de obra infantil, ao contrastar os anos de 2004, ano de unificação de outros programas de transferência de renda condicionada, e o ano de 2011, para uma análise mais atualizada. Fazendo uso da Pesquisa Nacional de Amostra de Domicílios (PNAD/IBGE) e dos dados disponibilizados pelo Ministério de Desenvolvimento e Combate à Fome (MDS), busca-se expor as informações obtidas por meio de dados expositivos e análise do mesmo. Além disso, ainda se promove um debate sobre o trabalho infantil visto pela ótica do desenvolvimento humano em perspectiva nacional e internacional. Ao fim da análise realizada, foi constada que apesar das condicionalidades exigidas de frequência escolar mínima, as crianças de 6 a 15 anos exercem trabalhos remunerados, geralmente no setor agrícola, o que implica dizer que o ingresso das famílias no Programa se mostra indiferente na decisão das crianças trabalharem ou não.
\end{abstract}

Palavras chaves: Trabalho infantil. Condicionalidade. Programa Bolsa Família.

\begin{abstract}
Given the great importance of the Bolsa Família Program (PBF) in immediate aid to poor families to increase income and fulfillment of conditionalities for receiving the benefit, became relevant check the indirect impact of the program on children engaging in some activity complementation family income. Thus, with increasing minimum attendance required to stay in the program, we intend to verify whether
\end{abstract}

\footnotetext{
"Mestranda em Economia Aplicada pela Universidade Federal de Alagoas. Graduada em economia pela Universidade Federal de Pernambuco

${ }^{* *}$ Doutora em Economia pelo PIMES/UFPE. Professora Adjunta da Universidade Federal de Pernambuco (UFPE), campus Agreste.
} 
this was reduced child labor, the contrast between 2004, the year of unification of other programs of conditional cash transfers, and 2011, for a more updated. Making use from the National Household Sample Survey (PNAD / IBGE) and data provided by the Ministry of Development and Fight against Hunger (MDS), seeks to expose the information obtained through data analysis and exhibition of the same. Besides that promotes debate on child labor seen from the perspective of human development in national and international perspective. At the end of the analysis, revealed as being that despite conditionalities required minimum school attendance, children 6 to 15 years performing paid work, usually in the agricultural sector. What implies that the inflow of families in the program was indifferent in the decision of children to work or not.

Keywords: Child labor. Conditionality. Bolsa Família Program.

\section{Introdução}

De início, o combate à pobreza pede ações específicas capazes de romper essa armadilha entre gerações, dentre as quais, destaca-se o papel dos programas de transferências focalizadas de renda. Um programa desta natureza tem por objetivo eliminar e/ou amenizar, no curto prazo, as dificuldades acarretadas pela condição de pobreza dessas famílias carentes (FERRO, 2003).

A implementação de programas de transferência direta de renda tem gerado um considerável interesse entre os formuladores de políticas públicas e no mundo acadêmico, no sentido de se avaliar seus benefícios a partir da redução da desigualdade ou concentração de renda.

A partir da década de 1990, muitos países em desenvolvimento adotaram novos formatos de programas distributivos de renda. (PEDROZO, 2007; SILVA, 2010, p. 63). No cenário nacional, este tema começa ser discutido com a aprovação pelo Senado, em dezembro de 1991, do Projeto de Lei $\mathrm{n}^{\mathrm{o}}$ 2561, de autoria do senador Eduardo Suplicy, propondo a instituição de um Programa de Garantia de Renda Mínima (PGRM), sob a forma de imposto de renda negativo ${ }^{1}$. Em 1995, na cidade de Campinas-SP, institui-se o Programa de Garantia de Renda Familiar Mínima (PGRFM) (FOGOÇA; 1998). No mesmo período, o governador do Distrito

\footnotetext{
${ }^{1}$ Imposto de renda negativo: sistema tributário que cobra imposto de famílias de renda alta e transfere renda às famílias de baixa renda. Disponível em: http://www.igf.com.br/aprende/glossario/glo_Resp.aspx?id=1616. Acesso em 18/12/2012.
}

Federal - Cristovam Buarque - cria o Programa Bolsa Escola tendo como objetivo central estimular a educação para crianças e adolescentes até então ausentes das salas de aula. No ano de 2001, este programa de transferência de renda direta começa ser implantado a nível Federal pelo então Presidente Fernando Henrique Cardoso, através do Sistema Brasileiro de Proteção Social e passa a ser composto por vários Programas Sociais de Transferência de Renda (auxílio-gás, bolsa escola, bolsa alimentação e cartão alimentação). Em 2004, através da Lei 10.836 de 9 de janeiro de 2004 o então Presidente da República Luís Inácio Lula da Silva promove a unificação dos Programas Sociais de Transferência de Renda implementados no Governo anterior ${ }^{2}$, denominando o novo programa de "Bolsa Família".

Em particular, a característica do Programa Bolsa Família (PBF), cuja política social é objeto central do Governo Federal até os dias atuais, configura-se como um programa de transferência de renda condicionada. Isso quer dizer que há compromissos assumidos tanto pelo governo federal, ofertando serviços de saúde, educação e assistência social,

\footnotetext{
${ }^{2}$ Programa Bolsa Família e Cadastro Único dos Programas Sociais do Governo Federal: Decreto no 3.877, de 24 de julho de 2001 Institui o Cadastramento Único para Programas Sociais do Governo Federal Medida Provisória $n^{\circ} 132$, de 20 de outubro de 2003 (convertida na Lei ${ }^{\circ} 10.836$, de 09 de janeiro de 2004) Cria o Programa Bolsa família e dá outras providências. Lei $n^{\circ} 10.836$, de 09 de janeiro de 2004 Cria o Programa Bolsa Família e dá outras providências. Decreto $n^{\circ} 5.209$, de 17 de setembro de $2004 \mathrm{Re}$ gulamenta a Lei no 10.836 , de 9 de janeiro de 2004, que cria o Programa Bolsa Família, e dá outras providências sobre o Cadastro Único de Programas Sociais do Governo Federal e sua repercussão sobre os benefícios dos programas de transferência de renda do Governo Federal. Disponível em: http://www.mds.gov.br. Acesso em: 06/12/2011.
} 
quanto pelas famílias beneficiárias, comprometendo-se a assumir estes compromissos para continuar recebendo o benefício ${ }^{3}$.

Uma das condicionalidades do Programa Bolsa Família está centrada na redução da probabilidade das crianças dessas famílias beneficiárias ingressarem precocemente no mercado de trabalho, para prover a complementação de renda da própria família. No entanto, esse objetivo tenderá ser alcançado através da permanência da criança na escola, um das principais condicionalidades do PBF.

Diante dessa perspectiva, o presente artigo discute, por meio de dados expositivos extraídos dos microdados da Pesquisa Nacional por Amostra de Domicílios (PNAD) dos anos de 2004 e 2011, se houve uma redução no ingresso precoce no mercado de trabalho de crianças entre 6 e 15 anos. Em outras palavras, este estudo revela se, no Brasil, o cenário que se refere ao trabalho infantil nesse período apresentou trajetória declinante.

\section{Trabalho Infantil}

Vasta é a literatura acadêmica definindo o trabalho infantil, permeando até mesmo a área jurídica no que se refere a este debate. Gonçalves (1997, p.3) afirma que talvez a melhor ideia que justifique a ocorrência do trabalho infantil como item de discussão social é que a infância e adolescência devem ser dedicadas à educação e à formação do indivíduo, e não ao trabalho. No que se refere à educação, a ocupação neste estágio da vida pode inviabilizar a frequência às aulas, ao concorrer sincronicamente a elas. O trabalho ainda pode reduzir a qualidade do aproveitamento escolar, ao exigir em demasia da criança ou do adolescente, dificultando-lhes o aprendizado intelectual e desestimulando sua continuidade, gerando como consequência a evasão escolar.

Essa realidade pode ser vista sob a ótica de que a partir do momento que as atividades exercidas se tornam uma necessidade de sustento e sobrevivência da família e que se tornam atividades regulares, nesse momento passam a ser consideradas como exploração da mão de obra infantil.

\footnotetext{
${ }^{3}$ Disponível em http://www.mds.gov.br/bolsafamilia/condicionalidades. Acesso em 09/12/2012.
}

Torres (2011) e Kassouf (2007) argumentam que a exploração da mão de obra infantil foi relatada por pensadores clássicos como Marx, Marshall, Engels e Thompson.

Kassouf (2007, p. 324) aponta que Marx (1867) já descrevia algumas causas do trabalho de crianças e adolescentes. Segundo ele, com o advento da máquina a força muscular nas tarefas foi reduzida, permitindo ao empregador oferecer ocupações que exigissem operários fracos ou com o desenvolvimento muscular incompleto. E com o tempo de serviço reduzido, o empregador reduz também o salário pago e seu meio de sobrevivência.

Ainda a partir da análise sobre Marshall (1929), Kassouf (2007) destacou em suas observações que as jornadas longas de trabalho de crianças já ocorriam no século XVII, ou seja, antes da revolução industrial. Durante a Revolução Industrial, o que descreve como o auge da miséria, era possível se deparar com uma forte fragilidade tanto psicológica quanto física, ambas causadas pelo excesso de trabalho.

As autoras Cacciamali (2008) e Kassouf (2005) verificam que Pigou (1932) defendia a erradicação do trabalho infantil, mas ciente de que impedir as crianças de trabalhar poderia levar algumas famílias em situação pior do que se encontravam. Diante disso, previne que um meio de erradicação do trabalho infantil deveria ser por meio de políticas públicas de assistência às famílias necessitadas.

Contudo, no Brasil, o trabalho infantil advém do período da escravidão, quando, os filhos de escravos acompanhavam seus pais nas mais diversas atividades e exerciam tarefas que exigiam esforços muito superiores às suas possibilidades físicas (KASSOUF, 2007, p. 324).

No cenário nacional, o trabalho infantil passou a ser questão de discussão pública devido ao emprego de crianças na indústria têxtil desde o século XIX, início da industrialização brasileira, como apresenta Torres (2011). A autora aponta que as condições precárias de trabalho em que crianças e adolescentes enfrentavam eram as mesmas das indústrias inglesas no período de iniciar a Revolução Industrial na Inglaterra: falta de higiene, precariedade na iluminação, sobrecarga e acidentes de trabalho no manuseio de máquinas, levando a problemas no desenvolvimento dos pequenos trabalhadores. 
Muniz(2006. p. 32 apud Ferreira, 2001) aponta que até meados dos anos 80 , no Brasil, o trabalho infantil não chegava a se constituir em um tema que despertasse interesse da sociedade. Pensavam muitos, até então, que o trabalho de crianças era uma alternativa positiva, disciplinadora e de ajuda à família. Segundo o autor, em todo mundo o tema despertava mais apatia, indiferença ou cinismo do que preocupação. Até então a única instituição internacional preocupada e empenhada em erradicar o trabalho precoce era a Organização Internacional do Trabalho (OIT). No entanto, no início da década de 90 iniciam-se algumas mudanças na condução do pensamento a respeito do trabalho infantil no Brasil, por exemplo, houve pressões internacionais que se tornaram uma verdadeira ameaça quando sanções comerciais norte-americanas recaíram sobre a produção de calçados na região de Franca/ Estado de São Paulo em 1994 ${ }^{4}$, colocando em risco a exportação deste produto (MUNIZ; 2006, p. 32 apud CARVALHO 2000). Logo, as pressões internacionais convergem a partir de então para o que se denomina de cláusulas sociais ${ }^{5}$.

No cenário nacional, a proteção à criança com o objetivo de garantir seus direitos na sociedade ganha um grande reforço a partir do Estatuto da Criança e Adolescente, Lei $n^{\circ} 8.069$ de 13 de julho de $1990^{6}$, que define no artigo $2^{\circ}$ a idade para que um indivíduo seja considerado criança e adolescente no Brasil: "Considera-se criança, para os efeitos desta Lei, a pessoa até 12 (doze) anos de idade incompleto, e adolescente aquela entre doze e dezoito anos de idade".

\footnotetext{
${ }^{4}$ Alves $(2004$, p.2) destacou a brusca redução da contratação formal de trabalhadores no setor calçadista de Franca, de 36.609, em 1986, para apenas 19 mil trabalhadores no ano de 1996. Também aponta que no ano de 1994 ocorreu uma grande eclosão da crise no setor produtivo calçadista e expansão do movimento sindical local, aumentando a visibilidade do problema do uso de trabalho infantil e de mulheres (trabalho domiciliar) associados ao movimento de subcontratação de trabalhadores pelos ateliês, que são organizações prestadoras de serviços à indústria, em condições e relações de trabalho tipicamente informal. Disponível em: http://www.ead.fea. usp.br/semead/7semead/paginas/artigos\%20recebidos/Socioambiental/ SA09_Desafios_de_Governan\%E7a_da_RSocial_Cadeia_.PDF. Acesso em: 06/01/2013.

${ }^{5}$ Por isso mesmo, elas geram tanta polêmica e resistência. Se de um lado, elas são saudadas como positivas por eliminar violações de direitos dos trabalhadores e dos consumidores (quando pensadas em termos de melhoria de qualidade dos produtos), por outro, podem legitimar novas práticas de protecionismo comercial introduzindo novas justificativas às sanções comerciais.

6 Disponível em: https://www.planalto.gov.br/ccivil_03/leis/l8069.htm. Acesso em 21/12/2012.
}

A partir dos anos 90, a preocupação começou a ganhar importância na sociedade brasileira. Primeiramente como uma forma de denúncia, principalmente na área agrícola, por meio de sindicatos dos trabalhadores, ministério público, as delegacias regionais do trabalho e outros órgãos públicos de defesa de cidadania (VEIGA; 1998, p. 89). Em 1995, a Confederação Nacional dos Trabalhadores na Agricultura divulgou um levantamento constando que cerca de $40 \%$ da força de trabalho na zona rural era composta de crianças. Além disso, 39\% do total de crianças em atividades de jornada de trabalho superior a 44 horas semanais, sendo que a maior parte delas trabalhava exposta a situações de risco.

No entanto, é através do artigo 60 do Estatuto da Criança e Adolescente quanto no artigo 403 da Lei $\mathrm{n}^{0}$ 10.097, de 19 de dezembro de 20007, sancionada pelo então Presidente da República Fernando Henrique Cardoso, que se procura caracterizar e identificar o trabalho de menor aprendiz: "É proibido qualquer trabalho a menores de dezesseis anos de idade, salvo na condição de aprendiz, a partir dos quatorze anos".

Além disso, a Lei no 10.097 também faz menção à remuneração e direitos trabalhistas devidos ao trabalho de menor aprendiz, ou seja, assegura o salário mínimo por hora, anotação em carteira de trabalho, condicionada à matrícula e frequência do menor na escola. Um passo também relevante foi a definição de idade mínima para considerar o menor aprendiz, que é de 14 anos até os 18 anos e a duração da jornada de trabalho de seis horas diárias, não podendo ser prorrogadas e nem compensadas. Além de os estabelecimentos empregadores de qualquer natureza serem obrigados a empregar e matricular nos cursos dos Serviços Nacionais de Aprendizagem para complementar a formação profissional desses aprendizes $^{8}$.

Atualmente, a Constituição Federal estabelece que somente a partir de 16 anos esteja permitida a admissão ao trabalho e ao emprego. Aúnica exceção à proibição constitucional é a admissão na condição de aprendiz, permitida a partir dos 14 anos (artigo $7^{\circ}$, inciso XXXIII), para tipos de atividades que

\footnotetext{
Disponível em: http://www.planalto.gov.br/ccivil_03/leis/L10097.htm Acesso em 21/12/2012.

${ }^{8}$ Disponível em: http://www.planalto.gov.br/ccivil_03/leis/110097.htm. Visitado em 21/12/2012.
} 
apresentem os requisitos legais para a aprendizagem profissional, previstos na CLT, com alterações introduzidas pela Lei $n^{\circ}$ 10.097/00 (ANDI; 2007, p.31). Logo, a legislação vigente apenas proíbe o trabalho infantil, não o caracteriza.

Deste modo, cabe à discussão a causa do trabalho infantil no Brasil e suas consequências para a entrada precoce de crianças no mercado de trabalho seja formal ou informalmente.

\section{Causas e Efeitos do Trabalho Infantil}

Na pesquisa de Ferro (2003, p.16), mostra-se que há relação entre pobreza e trabalho infantil, principalmente em centros urbanos. O autor conclui que há outros fatores importantes como o sistema educativo ineficiente, tradições e padrão social, falta de legislação e fiscalização, perfil do mercado e trabalho e os tipos de arranjo familiares. É por essa razão que o governo federal e alguns governos estaduais e prefeituras vêm institucionalizando programas de transferência condicionada, de modo que aumente a permanência das crianças e jovens na escola.

Santos (2010) e Kassouf (2002) concordam com os expostos de Monte (2008, p.647-648) ao afirmarem que caso não sejam executadas políticas públicas altamente eficientes, tende a resultar na continuidade da realidade de privação tanto social como econômica para as gerações futuras. Este fato vem ao encontro do que os autores concluem, ou seja, eles indicam que o trabalho infantil reduz os rendimentos provenientes do trabalho dos brasileiros na fase adulta da vida, independentemente do sexo ou região considerada.

Kassouf (2005) aponta que a questão de escolaridade dos pais da criança, a pobreza, o tamanho da família, idade em que os pais começaram a trabalhar, entre outras variáveis, são fatores importantes para explicar a alocação de tempo da criança ao trabalho. Trabalho infantil é uma atividade que gera benefícios imediatos na forma de renda, mas também gera custos por não estudar e/ou por reduzir o tempo de lazer. Assim sendo, fatores que afetam os benefícios do trabalho (salário), ou os custos (retornos à educação) também afetarão a decisão com relação ao trabalho infantil.

O estudo desenvolvido por Kassouf (2007, p. 339) mostra que o aumento da renda familiar reduz a probabilidade de a criança trabalhar e aumenta a chance de ela estudar. Isso afeta também a economia em níveis macroeconômicos, ou seja, observa-se que as nações que se tornaram mais ricas apresentaram uma redução no trabalho infantil. Tanto na China, como na Tailândia e na Índia, o crescimento do Produto Interno Bruto (PIB) desses países foi acompanhado pelo declínio do trabalho infantil.

No entanto, Oliveira (2004, p. 5-6) afirma, em sua pesquisa, que há uma estreita relação entre baixo nível de renda, baixo nível escolar e trabalho infantil devido à correlação entre qualificação e renda. $\mathrm{O}$ autor ainda utiliza o seguinte exemplo:

[...] uma família com pais de baixo nível escolar permitirão que em uma situação de onde tenham muitos filhos, permitirão que estes ingressem precocemente no mercado de trabalho na esperança de aumentar sua renda familiar. Ao ingressarem no mercado de trabalho, ocupando cargos de baixa qualificação ou nenhuma, as crianças não frequentarão o ensino regular ou se frequentarem terá baixo rendimento e consequentemente haverá repetência ou evasão escolar. Desse modo, o ciclo de pobreza se reinicia.

De acordo com a pesquisa de Monte (2008, p.647-648), os números mostraram que os indivíduos que começam a trabalhar ainda criança permanecem recebendo salários baixos mesmo quando adultos, indicando, assim, a existência de um ciclo vicioso de pobreza9 .

Monte (2008, p.648 apud Kassouf, 2002), afirma que uma pior inserção ocupacional corresponde a uma perspectiva limitada na carreira profissional dado que o sucesso profissional do trabalhador está fortemente atrelado ao seu status de origem. Mesmo tendo sido observado um retardamento no ingresso ocupacional dos indivíduos, a idade média de ingresso para os indivíduos nascidos na década de oitenta é superior em apenas 2,5 anos a idade média para os nascidos quarenta anos atrás $(15,0$ anos

\footnotetext{
${ }^{9}$ Ciclo vicioso de pobreza descrito por Nurske (1957, p.8) com um exemplo ao ser citado por Gumiero (2011, p.55): "um homem é pobre não tem o bastante para comer; sendo subalimentado, sua saúde é fraca; sendo fisicamente fraco, sua capacidade de trabalho é baixa, o que significa que ele é pobre, porque, por sua vez, quer dizer que não tem o bastante pra comer; e assim por diante. Tal situação transporta para um plano mais largo de um país." Disponível em: http://www.bdtd.ufscar.br/htdocs/tedeSimplificado/tde_arquivos/21/TDE-2011-05-30T160938Z-3739/Publico/3647.pdf. Acesso em: 07/01/2013.
} 
contra 12,5 anos), quando praticamente não existia a regulação do Governo no mercado de trabalho nem a difusão de pesquisas que mostram o impacto negativo da inserção precoce.

\section{Programa de Transferência Condicionada de Renda (PTCR)}

Os Programas de Transferência Condicionada de Renda (PTCR) têm ganhado espaço no cenário de política social nos países em desenvolvimento. Ferraz (2008, p.27) define os PTCR como uma política pública de transferência de renda direta para famílias pobres, que não tem em sua estrutura a exigência de determinados pré-requisitos para o recebimento desse benefício monetário, tais como: ações em saúde, educação e trabalho.

Apesar do conceito desenvolvido no início dos anos 1990 sinalizar para o desenvolvimento de programas de garantia de renda mínima, na verdade implementaram-se no Brasil programas de transferência de renda condicionada a partir de $1995^{10}$. A principal diferença é que, enquanto o único critério para os programas de garantia de renda mínima é a renda, os programas de transferência de renda condicionada também exigem contrapartida dos beneficiários. (SÁTYRO, 2009, p. 8).

Soares (2009, p.7) aponta que embora o Programa Bolsa Família tenha sido criado apenas em 2003, sua criação é consequência de uma trajetória particular em políticas de proteção social seguida pelo Brasil nos últimos 40 anos, em especial após a Constituição de 1988. Esta trajetória tem elementos em comum com outros países latino-americanos, mas também conta com aspectos peculiares ao nosso país.

\section{Programa Bolsa Família}

Segundo o Ministério do Desenvolvimento Social e Combate à Fome (MDS), o Programa Bolsa Família (PBF) é um programa de transferência

\footnotetext{
${ }^{10}$ Com os programas locais de renda mínima: Programa de Garantia de Renda Familiar Mínima, em Campinas, a Bolsa Familiar para Educação, no Distrito Federal, e Programa de Garantia de Renda Familiar Mínima, de Ribeirão Preto. Estes três programas limitavam-se a famílias com crianças menores que 14 anos e eram programas de transferência de renda condicionados, que exigiam contrapartidas dos seus beneficiários. (SÁTYRO, 2009, p. 8-9).
}

direta de renda que beneficia famílias em situação de pobreza (renda familiar per capita de $\mathrm{R} \$ 70,01$ a $\mathrm{R} \$ 140,00)$ e de extrema pobreza (renda familiar per capita de até R\$ 70,00). Criado em 20 de outubro de 2003 pela Medida Provisória $n^{0} 132$, foi legitimado pela Lei $\mathrm{n}^{\circ} 10.836$, de 09 de Janeiro de 2004, e pelo Decreto ${ }^{\circ}$ 5.209, de 17 de setembro de 2004. O Programa tem como objetivo principal combater a pobreza no Brasil e para isso atua em três frentes: a transferência de renda promove o alívio imediato da pobreza, as condicionalidades reforçam o acesso a direitos sociais básicos nas áreas de educação, saúde e assistência social, e as ações e programas complementares objetivam o desenvolvimento das famílias, de modo que os beneficiários consigam superar a situação de vulnerabilidade. ${ }^{11}$

A partir da discussão no que tange a permanência das famílias no Programa, Tavares (2010, p. 616) elaborou uma pesquisa em que aponta que a implantação de políticas sociais pode incentivar mudanças de comportamento não desejáveis por parte dos beneficiários dos programas. Segundo o autor, quando se trata de programas de transferência de renda, o primeiro incentivo desfavorável suposto na pesquisa é o da redução da oferta de trabalho dos beneficiários, aumentando seu grau de dependência em relação ao programa, dada a redução da renda proveniente do trabalho. Tal fato representa o efeito-renda da transferência: diante do aumento da parcela da renda do domicílio, algum membro da família reduz sua oferta de trabalho sem comprometer o orçamento familiar.

No entanto, programas sociais como o Programa Bolsa Família, também supõem a existência de um efeito-substituição da transferência, decorrente da imposição de condicionalidades. Isso porque, como o programa atrela o recebimento do benefício à frequência das crianças às aulas, deve haver uma redução do trabalho infantil ofertado e, portanto, e também da renda proveniente do trabalho no domicílio. No entanto, para se manter a renda seria necessário que ela fosse compensada pelo aumento do trabalho de outro membro da família. Assim, o impacto do programa sobre a oferta de trabalho dos beneficiários não é conclusivo, uma vez que depende de dois efeitos (renda e substituição),

\footnotetext{
${ }_{11}$ Disponível em: < http://www.mds.gov.br/bolsafamilia>. Acesso em: 19/01/2013.
} 
que atuam em sentidos opostos.

O Programa Bolsa Família define o cumprimento de algumas condicionalidades relacionadas às áreas da saúde e educação. A expectativa, segundo justificativa explicitada na legislação e documentos oficiais do Programa, é de que o cumprimento de condicionalidades tanto possibilite o acesso e a inserção da população pobre nos serviços sociais básicos como favoreça a interrupção do ciclo de reprodução da pobreza (SENNA, 2007, p.89).

As condicionalidades, definidas pelo Ministério de Desenvolvimento Social, são os compromissos assumidos tanto pelas famílias beneficiárias do Bolsa Família quanto pelo poder público para ampliar o acesso dessas famílias a seus direitos sociais básicos. Por um lado, as famílias devem assumir e cumprir esses compromissos para continuar recebendo o benefício. Por outro, as condicionalidades responsabilizam o poder público pela oferta dos serviços públicos de saúde, educação e assistência social.

$\mathrm{Na}$ área de saúde, as famílias beneficiárias assumem o compromisso de acompanhar o cartão de vacinação e o crescimento e desenvolvimento das crianças menores de 7 anos. As mulheres na faixa de 14 a 44 anos também devem fazer o acompanhamento e, se gestantes ou nutrizes (lactantes), devem realizar o pré-natal e o acompanhamento da sua saúde e do bebê.

$\mathrm{Na}$ educação, todas as crianças e adolescentes entre 6 e 15 anos devem estar devidamente matriculados e com frequência escolar mensal mínima de $85 \%$ da carga horária. Já os estudantes entre 16 e 17 anos devem ter frequência de, no mínimo, $75 \%$. Na área de assistência social, crianças e adolescentes com até 15 anos em risco ou retiradas do trabalho infantil pelo Programa de Erradicação do Trabalho Infantil (PETI), devem participar dos Serviços de Convivência e Fortalecimento de Vínculos (SCFV) do PETI e obter frequência mínima de $85 \%$ da carga horária mensal. Esgotadas as chances de reverter o descumprimento das condicionalidades, a família pode ter o benefício do Bolsa Família bloqueado, suspenso ou até mesmo cancelado.

À luz das condicionalidades do Programa Bolsa Família, mais especificadamente quanto à condicionalidade de educação, podem-se observar alguns impactos ao longo dos anos.
A partir de dados do Instituto Nacional de Estudos e Pesquisas Educacionais Anísio Teixeira (INEP) para os anos de 2007 a 2011, sobre a taxa de abandono escolar no ensino fundamental, há uma redução de $3,7 \%$, para os estados que compõem a região Norte e Nordeste do país. No entanto, ao analisar o ano de 2011, verifica-se que essas regiões apresentam as maiores taxas de abandono escolar nesta faixa etária no país, $7,7 \%$ e $8,3 \%$ respectivamente. Muito contrastante com os estados do Sul e Sudeste do pais que permearam entre $2,2 \%$ e $1,4 \%$ de taxa de abandono escolar para o mesmo período.

Na pesquisa organizada por Neri (2009, p.58), com base nas Pesquisas Nacionais por Amostra de Domicílios (PNAD) de 2004 e 2006, aponta que o principal motivo para a evasão escolar apresentado seria a falta de oferta de vaga escolar no grupo etário de 7 a 14 anos (crianças que frequentam o ensino fundamental).

Ferro $(2003$, p.441) argumenta que as transferências de renda tiveram um impacto positivo e significativo sobre a redução da jornada de trabalho de crianças entre 6 e 15 anos de idade pertencentes a famílias com renda per capita inferior a meio salário mínimo, mas nada poderia ser afirmado sobre a decisão de trabalhar ou não. No entanto, Tavares (2010, p. 630), em sua pesquisa, salienta que o recebimento do beneficio impactaria positivamente para a redução do trabalho infantil, desde que cumprida a sua condicionalidade.

Diante desse contexto, a proposta desse estudo é verificar se o trabalho infantil no Brasil entre os anos de 2004 e 2011 se apresenta em trajetória crescente ou decrescente após a unificação do Programa Bolsa Família realizado do ano de 2004.

\section{Condições de trabalho}

A seguir, serão dispostas as informações colhidas da Pesquisa Nacional de Amostra de Domicílios de 2004 e 2011 (PNAD/IBGE), a respeito das condições de trabalho de crianças entre 6 a 15 anos. Inicialmente apresentados na tabela 1.

Os dados colhidos apontaram que trabalho não remunerado nesta faixa etária em 2004 foi da ordem de $51,94 \%$ e reduziu para $39,68 \%$ em $2011^{12}$.

\footnotetext{
${ }^{12}$ Reforça-se que a partir de 14 anos de idade, é permitido que a criança
} exerça atividade remunerada ao ser enquadrada como menor aprendiz e 
Pedrozo (2007, p. 14) apresenta em sua pesquisa resultados que corroboram com estes dados, pois segundo o autor afirma, ao ser inserido no Programa Bolsa Família, aumenta a frequência escolar sem necessidade de a criança trabalhar, principalmente entre famílias caracterizadas pelo Programa como pobres. Entretanto, nas categorias trabalhador doméstico sem carteira assinada, outro empregado também sem carteira assinada e trabalhador para o próprio consumo houve um aumento de 13\% das crianças que trabalhavam.

Na região Norte, observa-se uma redução significativa de crianças que trabalhavam sem remuneração em alguns estados, como no Amapá, que em 2004 foi de 85,29\%, caindo para 25\% em 2011. Entretanto, se verificado com mais atenção, neste mesmo estado aumentou significativamente o percentual de crianças que passaram a ocupar trabalhos domésticos e outros empregos sem carteira assinada ou passaram a trabalhar por conta própria ${ }^{13}$.

No Nordeste brasileiro, verifica-se a mesma trajetória, ou seja, houve uma redução em todos os estados da região no que se refere ao percentual de crianças que trabalhavam sem remuneração. No estado de Alagoas verifica-se uma variação de aproximadamente $75 \%$, no entanto, em uma análise através de uma visão mais preocupante, verifica-se que o estado do Ceará registrou uma redução de apenas $3,79 \%$ neste quesito entre 2004 e 2011. Sob a ótica do trabalho infantil, é possível verificar que o estado do Rio Grande do Norte apresentou um aumento na variação percentual de aproximadamente $200 \%$ de domicílios que possuíam crianças na faixa etária de 6 a 15 anos que declararam ser empregados domésticos sem carteira assinada.

Dando continuidade para análise que centra a região Nordeste, verifica-se que apenas um estado dessa região apresentou redução no percentual de crianças que trabalham na produção do próprio consumo, foi o estado da Paraíba (14,09\%), os outros estados apresentaram uma elevação muito significa- tiva neste quesito entre os anos de 2004 e 2011. E na categoria que se enquadrou com sendo empregado sem carteira assinada o estado que apresentou a maior variação percentual no período analisado foi Alagoas com 138,07\%. No lado oposto, encontra-se o estado do Ceará, onde se registrou a maior queda percentual neste quesito, aproximadamente $26,43 \%$.

Nos estados da região Sudeste verifica-se que em todos houve redução na variação percentual em relação às categorias de trabalho: crianças trabalhando sem remuneração no período analisado; as que declararam serem trabalhadoras por conta própria e as que afirmaram serem trabalhadoras domésticas sem carteira assinada. Exceto o estado do Rio de Janeiro que apresentou um leve aumento na última categoria, da ordem de $0,83 \%$ e uma elevação significativa de aproximadamente $48,91 \%$ de crianças que trabalhavam sem remuneração.

Quanto à região Sul, houve uma expressiva redução em todos os estados analisados dessa região no que se refere a crianças que trabalham sem remuneração, para o período observado. Entretanto, houve um aumento de $14,3 \%$ de crianças declaradas como trabalhadores sem carteira assinada. Principalmente no Estado de Santa Catarina, verifica-se um aumento percentual da ordem de $60,91 \%$ entre 2004 e 2011.

Na região Centro-oeste do país, verifica-se uma redução média de $43,38 \%$ de crianças sem remuneração ao exercer alguma atividade. Porém, entre 2004 e 2011, houve um aumento significativo de crianças trabalhando sem carteira assinada, em média 45,42\%. Em relação a esta última variável, o que é possível observar são os números encontrados para o Distrito Federal, os maiores valores entre as unidades federativas do país que compõem essa região. Entre categorias de trabalho doméstico sem carteira assinada e em atividades para o consumo próprio, houve uma redução em relação a essas categorias, em média, $37,74 \%$ e em $30,71 \%$, respectivamente. 
Tabela 1: Crianças de 6 a 15 anos por posição de ocupação, Brasil e Unidades da Federação, 2004 e 2011

\begin{tabular}{|c|c|c|c|c|c|c|c|c|c|c|}
\hline & & & 2004 & & & & & 2011 & & \\
\hline & \begin{tabular}{l}
\multicolumn{1}{c}{ não } \\
remune \\
- rado
\end{tabular} & $\begin{array}{c}\text { conta } \\
\text { própria }\end{array}$ & $\begin{array}{l}\text { trabalha- } \\
\text { dor } \\
\text { domés- } \\
\text { tico } \\
\text { sem } \\
\text { carteira } \\
\text { assinada } \\
(\%)\end{array}$ & $\begin{array}{c}\text { traba- } \\
\text { lha } \\
\text { sem } \\
\text { carteira } \\
\text { assina- } \\
\text { da } \\
(\%)\end{array}$ & $\begin{array}{c}\text { trabalha } \\
\text { na } \\
\text { produção } \\
\text { do } \\
\text { próprio } \\
\text { consumo } \\
(\%)\end{array}$ & \begin{tabular}{l}
\multicolumn{1}{c}{ não } \\
remune \\
- rado
\end{tabular} & $\begin{array}{l}\text { conta } \\
\text { própria }\end{array}$ & $\begin{array}{c}\text { trabalha- } \\
\text { dor } \\
\text { domés- } \\
\text { tico } \\
\text { sem } \\
\text { carteira } \\
\text { assinada } \\
(\%)\end{array}$ & $\begin{array}{l}\text { trabalha } \\
\text { sem } \\
\text { carteira } \\
\text { assina- } \\
\text { da }\end{array}$ & $\begin{array}{l}\text { traba- } \\
\text { lha } \\
\text { na } \\
\text { produçã } \\
\text { do } \\
\text { próprio } \\
\text { consumc } \\
(\%)\end{array}$ \\
\hline Brasil & 51,94 & 7,10 & 6,90 & 23,32 & 9,44 & 39,68 & 6,35 & 7,94 & 28,68 & 14,66 \\
\hline RO & 62,26 & 3,77 & 3,14 & 19,50 & 10,69 & 46,81 & 7,45 & 12,77 & 25,53 & 6,38 \\
\hline $\mathrm{AC}$ & 70,00 & 6,92 & 5,38 & 7,69 & 10,00 & 57,69 & 2,56 & 2,56 & 8,97 & 25,64 \\
\hline $\mathrm{AM}$ & 67,67 & 3,76 & 4,51 & 9,77 & 14,29 & 55,73 & 6,25 & 4,17 & 14,58 & 19,27 \\
\hline RR & 45,45 & 4,55 & 4,55 & 31,82 & 13,64 & 60,87 & - & 2,17 & 15,22 & 19,57 \\
\hline $\mathrm{PA}$ & 59,04 & 8,43 & 6,99 & 16,39 & 7,95 & 55,25 & 6,23 & 6,23 & 20,23 & 10,89 \\
\hline $\mathrm{AP}$ & 85,29 & 2,94 & 2,94 & 2,94 & 5,88 & 25,00 & 16,67 & 16,67 & 41,67 & - \\
\hline $\mathrm{TO}$ & 37,30 & 9,52 & 7,94 & 17,46 & 27,78 & 36,45 & 1,87 & 12,15 & 27,10 & 22,43 \\
\hline $\mathrm{MA}$ & 61,84 & 6,28 & 7,73 & 11,11 & 13,04 & 44,89 & 3,98 & 6,82 & 10,23 & 31,25 \\
\hline PI & 65,19 & 9,94 & 5,52 & 9,94 & 8,84 & 59,32 & 5,08 & 8,47 & 11,02 & 16,10 \\
\hline $\mathrm{CE}$ & 60,39 & 7,00 & 7,00 & 21,26 & 4,35 & 58,10 & 4,47 & 11,73 & 15,64 & 9,50 \\
\hline $\mathrm{RN}$ & 61,64 & 10,96 & 6,85 & 16,44 & 4,11 & 40,48 & 7,14 & 21,43 & 16,67 & 14,29 \\
\hline PB & 51,09 & 6,52 & 4,35 & 16,30 & 20,65 & 40,32 & 11,29 & 6,45 & 24,19 & 17,74 \\
\hline $\mathrm{PE}$ & 50,45 & 10,39 & 6,23 & 20,47 & 12,17 & 25,81 & 15,05 & 5,38 & 34,41 & 18,28 \\
\hline $\mathrm{AL}$ & 73,68 & 5,26 & 2,63 & 11,40 & 7,02 & 18,57 & 10,00 & 5,71 & 27,14 & 38,57 \\
\hline $\mathrm{SE}$ & 41,54 & 18,46 & 1,54 & 26,15 & 12,31 & 39,22 & 13,73 & 7,84 & 15,69 & 21,57 \\
\hline BA & 63,33 & 10,01 & 4,71 & 15,46 & 5,45 & 37,29 & 8,25 & 5,94 & 25,41 & 21,45 \\
\hline MG & 33,50 & 7,16 & 10,49 & 32,48 & 15,35 & 27,92 & 5,83 & 8,75 & 45,00 & 10,42 \\
\hline ES & 40,78 & 10,68 & 13,59 & 24,27 & 5,83 & 35,59 & 5,08 & 8,47 & 32,20 & 6,78 \\
\hline RJ & 16,87 & 18,07 & 14,46 & 44,58 & 1,20 & 25,00 & 14,58 & 14,58 & 43,75 & - \\
\hline $\mathrm{SP}$ & 20,49 & 9,84 & 7,79 & 55,74 & 0,82 & 12,98 & 6,87 & 6,11 & 58,02 & 6,87 \\
\hline PR & 46,73 & 2,61 & 7,84 & 29,74 & 12,75 & 27,45 & 7,84 & 8,50 & 45,10 & 6,45 \\
\hline $\mathrm{SC}$ & 60,22 & 1,66 & 5,52 & 29,83 & 2,76 & 24,00 & 4,00 & 8,00 & 48,00 & 2,00 \\
\hline RS & 52,47 & 2,86 & 5,71 & 22,86 & 11,43 & 41,81 & 2,26 & 7,91 & 32,20 & 12,99 \\
\hline MS & 45,16 & 2,15 & 9,68 & 25,81 & 12,90 & 21,21 & 6,06 & 6,06 & 60,61 & - \\
\hline MT & 37,95 & 2,41 & 8,43 & 39,16 & 12,05 & 27,45 & 4,84 & 8,06 & 48,39 & 4,84 \\
\hline GO & 34,85 & 4,55 & 12,12 & 43,43 & 3,03 & 26,21 & 4,85 & 13,59 & 41,75 & 4,85 \\
\hline DF & 14,29 & 7,14 & 14,29 & 57,14 & - & - & 10,00 & - & 90,00 & - \\
\hline
\end{tabular}

Fonte: PNAD/IBGE.

Elaboração própria.

A tabela 2, que segue, tem como objetivo classificar melhor o setor de ocupação das crianças que exercem alguma atividade. No Brasil, entre os anos pesquisados, observa-se que houve uma redução no percentual de $8,42 \%$ de crianças empregadas no setor agrícola. Os dados sobre os estados da região Norte do país revelam ainda um alto índice de crianças empregadas no setor agrícola, exceto no estado do Amapá, que registrou uma queda em torno de $86 \%$. No entanto, há uma mobilidade do trabalho infantil para as atividades de comércio, um aumento de $277,8 \%$, e em serviços domésticos, aumento de $467,0 \%$.
$\mathrm{Na}$ região Nordeste, verifica-se que alguns estados registraram redução no percentual de crianças inseridas em atividades agrícolas. O Rio Grande do Norte se depara com uma redução na variação percentual de aproximadamente $26,12 \%$, seguido pelo estado de Pernambuco, com cerca de $24,26 \%$ de trabalhadores de 6 a 15 anos em atividade agrícola.Ainda fazendo uma análise mais atenta para a região Nordeste, verifica-se que os estados de Maranhão, Piauí e Alagoas apresentam percentuais acima dos 70\% no ano de 2011 de crianças que trabalham no setor agrícola, valores elevados em relação aos demais estados dessa região, ou seja, 
apresentam os maiores percentuais de empregos agrícolas entre crianças de 6 a 15 anos na região Nordeste.

Entre os estados nordestinos, Sergipe destacase como o estado onde mais foram inseridas crianças no trabalho doméstico na região, com um aumento na variação percentual de aproximadamente $400 \%$ entre 2004 e 2011. No estado de Alagoas verificase aumento percentual de aproximadamente 100\% de crianças inseridas em outras atividades, entre esse período, e na Bahia, constata-se um aumento altamente significativo na variação percentual de crianças que estão trabalhando e inseridas no comércio e reparação.
Os estados das regiões Sul e Sudeste apresentaram uma redução nas atividades agrícolas de crianças de 6 a 15 anos, exceto os estados do Rio de Janeiro e São Paulo, que apresentação uma variação positiva da ordem de $(23,61 \%)$ e $(50,75 \%)$, respectivamente. Vale salientar, entretanto, que esses dois estados são os que apresentam os menores percentuais de crianças inseridas em atividades agrícolas registrados para as duas regiões. Entretanto há uma maior participação desta mão de obra em atividades de comércio e serviços, e em serviços domésticos houve um equilíbrio entre os anos observados,

O mesmo ocorreu nos estados que compõem o Centro-oeste brasileiro e no Distrito Federal. Houve

Tabela 2: Crianças 6 a 15 anos por grupo de atividade principal, Brasil e Unidades da Federação, 2004 e 2011

\begin{tabular}{|c|c|c|c|c|c|c|c|c|}
\hline & \multicolumn{4}{|c|}{2004} & \multicolumn{4}{|c|}{2011} \\
\hline & $\begin{array}{c}\text { Agrícola } \\
(\%)\end{array}$ & $\begin{array}{c}\text { comércio e } \\
\text { reparação } \\
(\%)\end{array}$ & $\begin{array}{l}\text { serviço } \\
\text { domestico } \\
(\%)\end{array}$ & $\begin{array}{c}\text { outros }{ }^{*} \\
(\%)\end{array}$ & $\begin{array}{c}\text { Agrícola } \\
(\%)\end{array}$ & $\begin{array}{c}\text { comércio e } \\
\text { reparação } \\
(\%)\end{array}$ & $\begin{array}{l}\text { serviço } \\
\text { domestico } \\
(\%)\end{array}$ & $\begin{array}{c}\text { outros } \\
(\%)\end{array}$ \\
\hline Brasil & 52,49 & 18,12 & 6,90 & 22,49 & 48,07 & 18,36 & 7,94 & 25,63 \\
\hline RO & 69,18 & 11,32 & 3,14 & 16,36 & 53,19 & 11,70 & 12,77 & 22,34 \\
\hline $\mathrm{AC}$ & 75,38 & 8,46 & 5,38 & 10,78 & 80,77 & 11,54 & 2,56 & 5,12 \\
\hline $\mathrm{AM}$ & 67.67 & 12.78 & 4,51 & 15,04 & 72,40 & 11,46 & 4,17 & 11,98 \\
\hline $\mathrm{RR}$ & 54,55 & 9,09 & 4,55 & 31.81 & 80,43 & 15,22 & 2,17 & 2.17 \\
\hline $\mathrm{PA}$ & 48,67 & 23,13 & 6,99 & 21,21 & 45,91 & 16,34 & 6,23 & 31,53 \\
\hline $\mathrm{AP}$ & 61,76 & 8,82 & 2,94 & 26,48 & 8,33 & 33,33 & 16,67 & 41,67 \\
\hline TO & 57,94 & 17,46 & 7,94 & 16,66 & 61,68 & 10,28 & 12,15 & 15,87 \\
\hline MA & 65,22 & 16,43 & 7,73 & 10,62 & 70,45 & 11,93 & 6,82 & 10,80 \\
\hline PI & 67,40 & 11,05 & 5,52 & 16,03 & 73,73 & 7,63 & 8,47 & 10,17 \\
\hline $\mathrm{CE}$ & 50,72 & 16,18 & 7,00 & 26,01 & 60,34 & 10,06 & 11,73 & 17,88 \\
\hline $\mathrm{RN}$ & 54,79 & 17,81 & 6,85 & 20,55 & 40,48 & 14,29 & 21,43 & 23,80 \\
\hline PB & 61,96 & 14,13 & 4,35 & 19,56 & 53,23 & 14,52 & 6,45 & 25,80 \\
\hline$P E$ & 52,52 & 21,96 & 6,23 & 19,29 & 39,78 & 24,73 & 5,38 & 30,11 \\
\hline $\mathrm{AL}$ & 83,33 & 6,14 & 2,63 & 7,90 & 70,00 & 7,14 & 5,71 & 17,15 \\
\hline $\mathrm{SE}$ & 49,23 & 18,46 & 1,54 & 30,77 & 62,75 & 17,65 & 7,84 & 11,76 \\
\hline $\mathrm{BA}$ & 61,41 & 1,77 & 4,71 & 32,11 & 51,16 & 20,79 & 5,94 & 22,11 \\
\hline MG & 46,80 & 17,65 & 10,49 & 25,06 & 31,67 & 24,17 & 8,75 & 35,42 \\
\hline $\mathrm{ES}$ & 49,51 & 18,45 & 13,59 & 18,45 & 40,68 & 22,03 & 8,47 & 28,79 \\
\hline $\mathrm{RJ}$ & 8,43 & 37,35 & 14,46 & 39,76 & 10,42 & 27,08 & 14,58 & 45,83 \\
\hline SP & 8,61 & 32,79 & 7,79 & 50,81 & 12,98 & 31,30 & 6,11 & 49,61 \\
\hline PR & 51,31 & 18,30 & 7,84 & 22,55 & 28,76 & 26,80 & 8,50 & 35,94 \\
\hline $\mathrm{SC}$ & 61,33 & 16,02 & 5,52 & 17,13 & 20,00 & 22,00 & 8,00 & 50,00 \\
\hline $\mathrm{RS}$ & 54,03 & 15,06 & 5,71 & 25,20 & 42,94 & 18,64 & 7,91 & 30,51 \\
\hline MS & 45,16 & 17,20 & 9,68 & 27,96 & 27,27 & 24,24 & 6,06 & 42,43 \\
\hline MT & 48,19 & 20,48 & 8,43 & 22,90 & 30,65 & 27,42 & 8,06 & 60,87 \\
\hline $\mathrm{GO}$ & 23,23 & 31,31 & 12,12 & 33,34 & 18,45 & 31,07 & 13,59 & 36,89 \\
\hline $\mathrm{DF}$ & 14,29 & 42,86 & 14,29 & 28,53 & 10,00 & 50,00 & - & 40,00 \\
\hline
\end{tabular}

Fonte: PNAD/IBGE.

Elaboração própria.

" Outras atividades industriais; indústria de transformação; construção; alojamento e alimentação; transporte, armazenagem e comunicação; administração pública; educação, saúde e serviços sociais; outros serviços coletivos, sociais e pessoais; outras atividades; atividades mal definidas ou não declaradas. 
uma redução nas atividades agrícolas, com no Mato Grosso e Mato Grosso do Sul onde se constata uma redução da ordem de $(36,40 \%)$ e $(39,41 \%)$, respectivamente, de 2004 para 2011.

Dentre os estados brasileiros que apresentam uma forte concentração de população nesta faixa etária em áreas rurais no ano de 2011 foram encontrados na região Norte do país. Como por exemplo, no caso dos estados do Acre e Roraima, que registraram valores de aproximadamente $80 \%$ de crianças trabalhando em atividades agrícolas. Esses valores vêm ao encontro dos estudos que revelam que nas regiões rurais registram-se as maiores taxas de fecundidade se comparada com as mulheres que vivem em áreas urbanas.

Nessa perspectiva, Stropasolas (2012, p.254) demonstra em seu estudo as características socioeconômicas das regiões Norte e Nordeste. É nessas regiões que se constata uma população em maior proporção rural, com médias mais baixas de instrução, menores médias de rendimento e maiores taxas de fecundidade, sendo 4,2 (rural) e 3,7 (urbana), respectivamente em 1991 e com que no final de 2000 houve um aumento nesta variação, de 3,2 (rural) e 2,7 (urbana).

Quanto ao número de horas trabalhadas semanalmente por crianças no Brasil, apresentadas na tabela 3 , nota-se que a maioria trabalha semanalmente entre 15 a 39 horas, quase uma jornada integral de trabalho, e que de 2004 a 2011 ocorreu um aumento de 3,70\% nessa classificação. Seguindo a mesma trajetória, é possível verificar entre aqueles que declararam trabalhar até 14 horas semanais apresentou uma evolução de $2,07 \%$ e uma redução de $15,83 \%$ entre aqueles que trabalham em horas superiores. Observa-se que de 2004 para 2011, a região Norte reduziu em média $23,77 \%$ o número de horas trabalhadas de crianças que trabalham de 15 a 39 horas semanais. Porém aumentou o percentual de horas de até 14 horas semanais em média acima de 90\%. Na região Nordeste, o percentual de crianças que afirmam trabalhar até 14 horas semanais, apresentou um aumento de $11,73 \%$ em média, entre 2004 e 2011. Já aquelas que afirmam trabalhar entre 15 e 39 horas semanais reduziram na média em torno de $7,78 \%$. O que poderia representar um avanço senão fosse o aumento das crianças que declararam trabalhar mais de 40 horas semanais, em média de $13,80 \%$ para a região.

Nos estados que compõem a região Sudeste, verifica-se que houve um aumento médio de 7,52\% entre aquelas crianças que exerciam uma atividade entre 15 e 39 horas semanal. O Sul do país também registra um aumento médio de $11,38 \%$ no quesito entre 15 a 39 horas trabalhadas semanalmente.

Verificando os estados que compõem a região Centro-Oeste, em relação àqueles que trabalham mais de 40 horas semanais, houve uma redução média da ordem de $12,98 \%$. Apesar do aumento médio de aproximadamente $41,26 \%$ dos que declararam trabalhar entre 15 e 39 horas semanais.

Nesse sentido, ao verificar as informações sobre as características das crianças, dos domicílios em que residem e das atividades exercidas, por algumas delas, como forma de complementação de renda, podemos confrontar com dados sobre o Programa Bolsa Família. É certo que algumas regiões em certos aspectos aqui analisados ainda carecem de maior atenção na melhoria nas condições de vida da população ali residente. Algumas características, como escolaridade, raça e condições sanitárias básicas podem refletir informações sobre a renda dessas famílias, no entanto estas variáveis não estão sendo alvo dessa pesquisa. Desse modo, a decisão de ofertar ou não mão de obra precocemente fica analisada neste estudo, somente sob a ótica econômica, ou seja, da renda monetária. 
Tabela 3: Horas habitualmente trabalhadas por semana por crianças 6 a 15 anos, Brasil e Unidades da Federação, 2004 e 2011

\begin{tabular}{|c|c|c|c|c|c|c|}
\hline & \multicolumn{3}{|c|}{2004} & \multicolumn{3}{|c|}{2011} \\
\hline & $\begin{array}{c}\text { Até } 14 \text { horas } \\
(\%)\end{array}$ & $\begin{array}{c}15 \text { a } 39 \\
\text { horas } \\
(\%)\end{array}$ & $\begin{array}{c}\text { Outras } \\
(\%)\end{array}$ & $\begin{array}{c}\text { Até } 14 \\
\text { horas } \\
(\%)\end{array}$ & $\begin{array}{c}15 \text { a } 39 \\
\text { horas } \\
(\%)\end{array}$ & $\begin{array}{c}\text { Outras } \\
(\%)\end{array}$ \\
\hline Brasil & 27,97 & 55,42 & 16,61 & 28,55 & $\overline{57,47}$ & 13,98 \\
\hline RO & 15,72 & 57,86 & 26,42 & 34,04 & 53,19 & 12,77 \\
\hline $\mathrm{AC}$ & 20,77 & 68,46 & 10,77 & 25,64 & 69,34 & 5,02 \\
\hline $\mathrm{AM}$ & 9,77 & 73,68 & 16,55 & 22,92 & 65,10 & 11,98 \\
\hline RR & 4,55 & 90,91 & 4,55 & 60,87 & 32,61 & 93,48 \\
\hline $\mathrm{PA}$ & 29,40 & 56,87 & 13,73 & 31,52 & 58,75 & 9,73 \\
\hline $\mathrm{AP}$ & 26,47 & 70,59 & 2,94 & 58,33 & 25,00 & 16,67 \\
\hline TO & 32,54 & 53,97 & 13,49 & 34,58 & 56,07 & 9,35 \\
\hline $\mathrm{MA}$ & 27,54 & 58,94 & 13,52 & 12,50 & 71,59 & 15,91 \\
\hline PI & 40,88 & 53,04 & 6,08 & 35,59 & 55,93 & 8,48 \\
\hline $\mathrm{CE}$ & 21,98 & 62,32 & 15,70 & 27,37 & 58,66 & 13,97 \\
\hline $\mathrm{RN}$ & 28,77 & 53,42 & 17,81 & 21,43 & 57,14 & 21,43 \\
\hline PB & 19,57 & 65,76 & 14,67 & 46,77 & 38,71 & 14,52 \\
\hline $\mathrm{PE}$ & 27,00 & 57,86 & 15,14 & 23,66 & 56,99 & 19,35 \\
\hline $\mathrm{AL}$ & 23,68 & 65,79 & 10,53 & 30,00 & 52,86 & 17,14 \\
\hline $\mathrm{SE}$ & 20,00 & 69,23 & 10,77 & 35,29 & 54,90 & 9,81 \\
\hline $\mathrm{BA}$ & 34,32 & 56,41 & 9,27 & 37,52 & 53,80 & 8,58 \\
\hline MG & 30,43 & 48,08 & 21,49 & 25,00 & 60,42 & 14,58 \\
\hline $\mathrm{ES}$ & 25,24 & 58,25 & 16,51 & 25,42 & 59,32 & 15,26 \\
\hline $\mathrm{RJ}$ & 27,71 & 44,58 & 27,71 & 29,17 & 41,67 & 70,84 \\
\hline SP & 21,72 & 49,59 & 28,69 & 29,77 & 54,20 & 16,03 \\
\hline PR & 34,31 & 45,10 & 20,59 & 26,80 & 48,37 & 24,83 \\
\hline $\mathrm{SC}$ & 24,31 & 56,91 & 18,78 & 20,00 & 70,00 & 30,00 \\
\hline $\mathrm{RS}$ & 31,69 & 52,47 & 15,84 & 34,46 & 53,67 & 11,87 \\
\hline MS & 44,09 & 33,33 & 22,58 & 9,09 & 57.58 & 33.33 \\
\hline MT & 26,51 & 50,00 & 23,49 & 12,90 & 67,74 & 19,36 \\
\hline GO & 30,81 & 41,92 & 27,27 & 19,42 & 62,14 & 18,44 \\
\hline $\mathrm{DF}$ & 14,29 & 42,86 & 42,85 & 20,00 & 50,00 & 30,00 \\
\hline
\end{tabular}

Fonte: PNAD/IBGE

Elaboração própria.

* De 40 a 44 horas; 45 a 48 horas; 49 horas ou mais; sem declaração.

\section{Beneficiários do Programa Bolsa Família}

Com base nos dados disponibilizados pelo site do Ministério de Desenvolvimento e Combate à Fome (MDS), foi elaborada a tabela 4, na qual está a proposta em demonstrar a quantidade de famílias beneficiárias do Programa Bolsa Família.

Entre 2004 e 2011, verifica-se que houve um aumento de aproximadamente 99,21\% de famílias beneficiárias pelo programa em abrangência nacional. Entre os estados da região Norte, verifica-se que Amapá (AP), Roraima (RR) e Pará (PA) foram os que mais aumentaram sua participação em nú- meros de beneficiários do Programa Bolsa Família, $385,0 \% ; 209,9 \%$ e $193,82 \%$, respectivamente. Sendo o de menor abrangência, o estado de Santa Catarina, apresentando uma redução de 52,39\% de famílias beneficiárias.

Entre os estados que compõem a região Norte, variaram entre $88 \%$ a $385 \%$ de aumento de famílias beneficiárias.

No Nordeste, houve um aumento de $89,15 \%$ entre 2004 e 2011. Entre os estados dessa região, os estados de Maranhão (MA), Sergipe (SE) e Pernambuco $(\mathrm{PE})$, foram os que registraram maiores 
percentuais de aumento no número de beneficiados do Programa Bolsa Família 137,06\%, 117,07\% e $109,65 \%$, respectivamente. Entretanto um dado relevante é que ao analisar os mesmos estados em 2011, houve uma redução da ordem de 5,32\%, em relação ao total de benefícios concedidos nacionalmente, para a região Nordeste.

Contudo, é na região Centro-oeste o menor percentual de benefícios concedidos, cerca de 4, 41\%, em 2004, e aproximadamente 5,37\%, em 2011. Para esta região, é o estado de Mato Grosso do Sul com maior aumento percentual ao contrastarmos 2004 e 2011, com 305,69\% a mais de benefícios concedidos. Entretanto, o aumento percentual de 2004 e 2011 no Centro-Oeste é de 21,76\%.

No Sudeste, o maior amento percentual se deu no estado do Rio de Janeiro (RJ), 270,02\% de novos benefícios concedidos. Diferente do estado de Minas Gerais (MG), com o menor aumento expressivo entre os estados dessa região, em 50,61\%, para o período observado. Contudo, no ano de 2004, Minas Gerais já contava com mais de 769.600 beneficiários, o maior para esse ano entre os estados do sudeste brasileiro. Em 2004, a região detinha 26,26\% de benefícios concedidos concentrados, já em 2011 reduziu-se para $24,68 \%$, uma queda de $6,01 \%$.

$\mathrm{Na}$ região Sul, em 2004, concentravam-se $10,62 \%$ dos benefícios concedidos, e em 2011, esse número reduziu para $7,75 \%$. O estado de Santa Catarina (SC) reduziu em mais de 50,0\% o número de benefícios concedidos de 2004 para 2011. O maior índice de redução do país. Já o Rio Grande do Sul (RS), aumentou em 336,8\%, para o mesmo período.

Observando mais atentamente a tabela 4, nota-se que no estado do Acre (AC), apresenta o menor aumento percentual de famílias beneficiárias pelo programa, $88,41 \%$, em relação aos demais estados do norte do país. Entretanto, Distrito Federal (DF) apresenta o menor aumento percentual entre os estados do Centro-oeste, 84,99\%.

No Nordeste, Paraíba (PB) teve o menor aumento percentual entre os estados do nordeste, 73,98\%. Seguido do Rio Grande do Norte (RN), aumento de 79,99\%, e Ceará (CE), aumento de $83,88 \%$. No entanto, o estado do Ceará, já contava com 585.564 benefícios concedidos em 2004, o segundo maior do nordeste. Maior concentrador de benefícios é o estado da Bahia, tanto em 2004 e 2011.

Desse modo, observa-se a nível estadual, a abrangência de famílias captadas pelo Programa Bolsa Família atinge níveis entre $85 \%$ a $90 \%$, na sua maioria em 2011. O que implica uma melhoria nas condições de vida e renda das famílias em maior risco de pobreza.

Recentemente, Constanzi (2010, p. 249) publicou junto ao Instituto de Pesquisa em Economia Aplicada (IPEA) um conjunto de pesquisas que corroboram com o os objetivos iniciais do Programa de redução através da melhoria da distribuição de renda no país. Em sua pesquisa, o autor aponta que mesmo com o programa tendo um orçamento de pagamento de benefícios da ordem de $0,38 \%$ do PIB do Brasil, seu caráter possui características altamente redistributiva. Além disso, sua ampla cobertura (mais de 12,7 milhões de famílias) vem garantir ao programa resultados positivos em termos de redução da desigualdade ao observar o país no período recente.

Entretanto, o autor faz uma ressalva sobre o perfil dos beneficiários do Programa Bolsa Família, mostrando que os responsáveis legais, em quase $80 \%$ deles, não chegam a ter ensino fundamental completo. Fato que restringe a inserção no mercado de trabalho, em geral, a postos de trabalho de baixa qualidade, no setor informal e com baixas remunerações. Portanto, aponta que há uma tendência estrutural à precariedade de inserção dos responsáveis legais no mercado de trabalho, e que cerca de dois terços deles tenham idade entre 25 e 44 anos. Fato este que o faz concluir que o perfil socioeconômico do beneficiário, deve ser considerado nos debates que tangem a evolução futura do programa. 
Tabela 4: Quantidade de famílias que recebem do Programa Bolsa Família com crianças com idade entre 6 e 15 anos, Brasil e Unidades da Federação, 2004 e 2011

\begin{tabular}{lc|c} 
& 2004 & 2011 \\
\hline Brasil & $\mathbf{6 . 7 0 2 . 3 8 8}$ & $\mathbf{1 3 . 3 5 2 . 3 0 6}$ \\
RO & 56.072 & 112.950 \\
AC & 29.866 & 56.272 \\
AM & 106.892 & 307.285 \\
RR & 14.706 & 45.575 \\
PA & 262.848 & 772.311 \\
AP & 10.466 & 50.832 \\
TO & 56.295 & 131.714 \\
MA & 388.092 & 920.048 \\
PI & 224.681 & 444.696 \\
CE & 585.564 & 1.076 .764 \\
RN & 194.222 & 349.595 \\
PB & 280.363 & 487.779 \\
PE & 532.236 & 1.115 .851 \\
AL & 221.070 & 425.137 \\
SE & 116.613 & 253.134 \\
BA & 854.418 & 1.752 .993 \\
MG & 769.617 & 1.159 .172 \\
ES & 124.313 & 192.365 \\
RJ & 198.609 & 734.902 \\
SP & 667.590 & 1.209 .819 \\
PR & 313.173 & 444.050 \\
SC & 295.707 & 140.774 \\
RS & 103.178 & 450.778 \\
MS & 33.140 & 134.447 \\
MT & 171.905 \\
GO & 333.567 \\
DF & 137.921 & 77.591 \\
\hline
\end{tabular}

Elaboração própria.

Fonte: MDS e TCU.

No que se refere ao trabalho infantil, a ideia implícita no Programa Bolsa Família é que maior tempo dedicado à escola, diminui a disponibilidade das crianças para o trabalho infantil. No caso do Programa Bolsa Família é uma condicionalidade para a permanência da família no Programa.

Silva (2010, p. 97 apud Soares, Ribas e Osório, 2007) ressalta que o Programa Bolsa Família teve impacto positivo sobre a frequência escolar, com probabilidade de ausência ao mês de 3,6\% menos entre crianças de famílias beneficiárias e a evasão seria 1,6\% maior entre famílias não beneficiárias. Contudo, as crianças de famílias beneficiárias tinham 4\% maior de chance de serem reprovadas.

A autora ainda aponta que deve haver certa cautela nos dados expostos na sua pesquisa, pois apesar de as crianças inseridas no Programa Bolsa Família estarem abandonando menos a escola não necessariamente pode estar levando uma diminuição da aprovação escolar. Dando continuidade, conclui-se que a inserção do aluno na escola não é suficiente para romper com o ciclo de pobreza, pois é necessário levar em consideração um ensino de boa qualidade. 


\section{Análise conclusiva}

Quando analisadas as condições de trabalho, para aquelas que declaram exercer alguma atividade, observa-se uma redução das crianças entre 6 e 15 anos que trabalham sem remuneração. Mas houve um aumento em outras ocupações sem carteira assinada, caracterizando-se como empregados informais ou como trabalhadores para o próprio consumo.

Ao verificar em que setor encontra-se essa mão de obra infantil, observa-se que ao contrastar os anos 2004 e 2011, não houve uma redução tão significativa de atividades ligadas ao setor agrícola, serviços domésticos ou ligados ao comércio no período analisado. Alguns estados chegaram a aumentar os seus índices de crianças trabalhando ou mantiveram um percentual de equilíbrio quando comparados os anos do estudo.

Ao confrontar com dados das famílias beneficiárias pelo Programa Bolsa Família, é possível verificar um aumento significativo em todos os estados brasileiros. O que significa que o Programa Bolsa Família impacta positivamente no aumento de renda dessas famílias. O objeto deste trabalho é verificar a redução do trabalho infantil, dado que com o cumprimento das condicionalidades exigidas para a permanência no Programa, a criança em idade escolar frequentaria a escola e deixaria de exercer alguma atividade para ajudar na complementação de renda da família.

Os dados expostos nesta pesquisa relacionamse com pesquisas realizadas anteriormente por Ferro (2003, p.441). O Programa Bolsa Escola, com as transferências de renda causou um impacto positivo e significativo sobre a redução da jornada de trabalho de crianças entre 6 e 15 anos de idade pertencentes a famílias com renda per capita inferior a meio salário mínimo. Todavia, nada poderia ser afirmado sobre a decisão de trabalhar ou não.

Contudo, o desenho institucional do Programa Bolsa Família é melhoria na distribuição de renda e retirada do maior número de pessoas em situação de extrema pobreza. O impacto de reduzir o trabalho infantil seria algo implícito no Programa Bolsa Família, no entanto, de acordo com os dados expostos, não se consegue constatar a efetividade na redução do trabalho infantil dentro dessa faixa etária. Porém nota-se uma redução nos índices, sendo que se deve ser levar em conta o período de tempo analisado nesta pesquisa: o ano de 2004 é período em que é feita a unificação dos programas condicionados de renda e 2011, obtém-se os dados mais recentes para que fosse realizada a investigação.

\section{Referências}

CACCIMALI, Maria Cristina; TATEI, Fábio. Trabalho infantil e o status ocupacional dos pais. Revista de Economia Política. Vol. 28, $\mathrm{n}^{\mathrm{o}} 2$ (110), pp. 269-290, abril-junho 2008. Disponível em:< http://www.scielo.br/ scielo.php?pid $=$ S0101-31572008000200006\&script $=$ sci arttext\&tlng=es>. Acesso em: 20 dez. 2012.

CONSTANZI, R. N.; FAGUNDES, F. Perfil dos beneficiário do Programa Bolsa Família. In: CASTRO, Jorge Abrahão de; MODESTO, Lúcia (Orgs.). Bolsa Família 20032010: avanços e desafios. Brasília: Ipea, 2010. 1 v. pp. 249-270. Disponível em: <http://www.ipea.gov.br/portal/ index.php?option $=$ com content $\&$ view $=$ article $\&$ id $=6604>$. Acesso em: 17 jul. 2013.

FERRAZ, Lúcia Flávio. Programa Bolsa Família: Impactos na distribuição de renda. Monografia. Brasília: Instituto Serzedello Corrêa. 2008. Disponível em: < http://portal2. tcu.gov.br/portal/pls/portal/docs/2055562.PDF>. Acesso em: 29 jan. 2013.

FERRO, Andrea Rodrigues; KASSOUF, Ana Lúcia. Avaliação do impacto dos Programas Bolsa Escola no trabalho infantil no Brasil. Dissertação de Mestrado. Piracicaba: ESALQ/USP, 2003. Disponível em: < http:// www.anpec.org.br/encontro2003/artigos/F32.pdf> Acesso em: 25 nov. 2011.

FOGAÇA, José R. Complementando a Renda no Ramal da Fome: o estudo de um Programa de Renda Mínima. Dissertação de Mestrado. Campinas: UNICAMP, 1998. Disponível em: <http://www.bibliotecadigital.unicamp.br/ document/?code=vtls000134251 $>$. Acesso em 17 dez. 2012.

GONÇALVES, Renato. Trabalho infantil e a agenda social. Revista do BNDES, 1997. Disponível em: <http://www. bndes.gov.br/SiteBNDES/export/sites/default/bndes pt/ Galerias/Arquivos/conhecimento/revista/rev709.pdf>. Acesso em: 22/ dez. 2012.

KASSOUF, Ana Lúcia. O efeito do trabalho infantil para os rendimentos dos jovens, controlando o background familiar. Ouro Preto: XIII Encontro da Associação Brasileira de Estudos Populacionais. Novembro, 2002. Disponível em: $<\mathrm{http} / / /$ www.abep.nepo.unicamp.br/docs/anais/pdf/2002/ GT_TRB_ST18_Kassouf_texto.pdf>. Acesso em: 06 jan. 2013.

KASSOUF, Ana Lúcia. Trabalho infantil: causas e consequências. Apresentação no concurso de Professor 
titular do Depto. de Economia. Piracicaba: ESALQ/USP, 2005. Disponível em: < economia.esalq.usp.br/pesq/pesq57.pdf >. Acesso em: 28 nov. 2012

KASSOUF, Ana Lúcia. O que conhecemos sobre o trabalho infantil? Belo Horizonte: Revista Nova Economia, v. 17, n. 2, pp. 323-350, mai/ago. 2007. Disponível em: $<\quad$ http://www.scielo.br/scielo.php?pid=S01033512007000200005\&script=sci_arttext\&tlng=esja.org $>$. Acesso em: 28 nov. 2012

MONTE, Paulo Aguiar. Exploração do Trabalho Infantil no Brasil: Consequências e Reflexões. Brasília: Revista Economia, v.9, n. 3, 625-650, set/ dez 2008. Disponível em: $<$ http://www.anpec.org.br/revista/vo19/vo19n3p625_650. pdf $>$ Acesso em: 12 dez. 2012.

MUNIZ, André Luiz Pires; NEDER, Henrique Dantas. As caracteristicas e os determinantes do trabalho infantil em Minas Gerais em 2004. Dissertação de Mestrado. Uberlândia: UFU, 2006. Disponível em: $<$ www.portal. ie.ufu.br/mestrado/ie_dissertacoes/2006/6.pdf >. Acesso em: 25 nov. 2012.

NERI, Marcelo Côrtes. Motivos da Evasão Escolar. Rio de Janeiro: FGV/IBRE, 2009. Disponível em:< http://www.cps.fgv.br/ibrecps/rede/finais/Etapa3-Pesq MotivacoesEscolares_sumario_principal_anexo-Andre FIM.pdf>. Acesso em: 02 fev. 2013.

OLIVEIRA, Érica Diniz; RAMOS, Carlos Alberto. Trabalho Infantil: causas, consequências e políticas sociais. Brasília: UNB, 2004. Disponível em: <http://vsites.unb.br/face/eco/ peteco/dload/monos_022003/erica.pdf>. Acesso em: 21 dez. 2012.

PEDROZO, Euclides. Uma avaliação ex-ante dos impactos do Bolsa Família na redução do trabalho infantil. Anais do XXXII Encontro Nacional de Economia, 2007. Disponível em: < http://www.anpec.org.br/encontro2007/artigos/ A07A002.pdf > . Acesso em: 02 dez. 2012.

RELATÓRIO DA ORGANIZAÇÃO INTERNACIONAL DO TRABALHO (OIT). Boas Práticas em Comunicação. Um guia para fontes de informação. Supervisão editorial Veet Vivarta; Programa Internacional para Eliminação do Trabalho Infantil (IPEC). Brasília, 2006 Disponível em: $<$ http://www.oitbrasil.org.br/sites/default/files/topic/ipec/ pub/boaspraticas_325.pdf $>$. Acesso em: $22 \mathrm{dez} .2012$.

\section{RELATÓRIO DO TRIBUNAL DE CONTAS DA UNIÃO}

SANTOS, Francisca Lia Girão; FRANCO, Graziela Luiz. Políticas de transferências de renda: uma análise do Programa Bolsa Família. A Economia em Revista, v. 18, n. 2, dez 2010. Disponível: http://eduem.uem.br/ojs/index.php/EconRev/ article/view/12922/8306>. Acesso em: 29 jan. 2013.

SANTOS, Marcelo Justus; KASSOUF, Ana Lúcia. Consequência do trabalho infantil no rendimento futuro do trabalho dos brasileiros: diferenças regionais e de gênero. Salvador: Encontro Nacional de Economia 2010. Disponível em: < http://www.anpec.org.br/encontro2010/ inscricao/arquivos/000-7bfe42d90954e5040f9bdae429f51e 3c.pdf>. Acesso em: 25 nov. 2012.

SÁTYRO, Natália; SOARES, Sergei. O Programa Bolsa Família: desenho institucional, impactos e possibilidades futuras. Texto para discussão $\mathrm{n}^{0} 1424$. Brasília. Outubro de 2009. Disponível em: <http://desafios.ipea.gov.br/ sites/000/2/publicacoes/tds/td_1424.pdf $>$ Acesso em: 25 dez. 2012.

SENNA, Mônica de Castro Maia; BURLANDY, Luciene; MONNERAT, Giselle Lavinas; SCHOTTZ, Vanessa; MAGALHÃES, Rosana. Programa Bolsa Família: nova institucionalidade no campo da política social brasileira?Florianópolis: Revista Kátal., v. 10, n. 1, p. 8694, jan/jun. 2007. Disponível em: <http://www.scielo.br/ pdf/rk/v10n1/v10n1a10.pdf> Acesso em: 29 jan. 2013.

SILVA, Maria O. S. Focalização e impactos do Bolsa Familia na população pobre e extremamente pobre. In SILVA, Maria Ozanira da Silva e (Coord.) Avaliando o Bolsa Família: unificação, focalização e impactos. São Paulo: Cortez, 2010, p.63-109.

SOARES, Luísa de Azevedo Senra. Transferências de renda: modalidades e finalidades. Brasília, 2010. Disponível em: $\quad<$ http://www.sinteseeventos.com.br/bien/pt/papers/ luisaazevedoTransferenciasderendanoBrasil.pdf $>$. Acesso em: 24 jan. 2013.

STROPASOLAS, Valmir Luiz. Trabalho Infantil no campo: do problema social ao objeto sociológico. Rio de Janeiro: Revista Latino-americana de Estudos do Trabalho, v.17, n. 27, 2012, p. 249-286. Disponível em: <http://relet. iesp.uerj.br/Relet_27/Cap\%C3\%ADtulo\%2010\%20-\%20 Trabalho\%20Infantil $\% 20$ no\%20Campo\%20RELET\%20 27\%20-\%20SE.pdf $>$. Acesso em: 27 jun. 2013.

TAVARES, Priscilla Albuquerque. Efeito do Programa Bolsa Família sobre a oferta de trabalho das mães. Campinas: Revista Economia e Sociedade, v. 19, n. 3 (40), p. 613-635, dez. 2010. Disponível em: <http://www.scielo.br/pdf/ecos/ v19n3/08.pdf>. Acesso em: 01 fev. 2013.

TORRES, Maria Adriana. Trabalho Infantil: trabalho e direitos. Maceió: EDUFAL, 2011

VEIGA, João Paulo. A questão do trabalho infantil. São Paulo: Associação Brasileira de Estudos do Trabalho. Coleção ABET, vol. 7. 1998, pp. 89-94.

Sites:

www.ibge.gov.br www.inep.gov.br www.mds.gov.br/

Submissão: 23/07/2013

Aprovação: 10/2014 